\title{
Effect of Ginkgo biloba on the reproductive outcome and oxidative stress biomarkers of streptozotocin- induced diabetic rats
}

M.V.C. Rudge ${ }^{1}$ D.C. Damasceno ${ }^{1}$, G.T. Volpato ${ }^{1}$, F.C.G. Almeida ${ }^{1}$, I.M.P. Calderon ${ }^{1}$ and I.P. Lemonica ${ }^{2}$
${ }^{1}$ Laboratório de Pesquisa Experimental de Ginecologia e Obstetrícia, Departamento de Ginecologia e Obstetrícia, ${ }^{2}$ Departamento de Patologia, Faculdade de Medicina de Botucatu, Universidade Estadual Paulista, São Paulo, SP, Brasil

\section{Correspondence \\ M.V.C. Rudge \\ Departamento de Ginecologia e \\ Obstetrícia, FMB, UNESP \\ Distrito de Rubião Júnior, s/n \\ 18618-000 Botucatu, SP \\ Brasil \\ E-mail: mrudge@reitoria.unesp.br \\ Research supported by FAPESP (No. 99/10167-0).}

Received September 22, 2006 Accepted April 20, 2007

\begin{abstract}
The aim of the present study was to evaluate the effect of Ginkgo biloba treatment (EGb 761, $200 \mathrm{mg} \mathrm{kg}^{-1} \mathrm{day}^{-1}$ ) administered from day 0 to 20 of pregnancy on maternal reproductive performance and on the maternal and fetal liver antioxidant systems of streptozotocin-induced diabetic Wistar rats. On day 21 of pregnancy, the adult rats (weighing approximately $250 \pm 50 \mathrm{~g}$, minimum number $=13$ (group) were anesthetized to obtain maternal and fetal liver samples for superoxide dismutase (SOD), catalase (CAT), glutathione peroxidase (GSH-Px), and total glutathione (GSH-t) determinations. The uterus was weighed with its contents. The diabetic (G3) and treated diabetic (G4) groups of rats presented significant maternal hyperglycemia, reduced term pregnancy rate, impaired maternal reproductive outcome and fetal-placental development, decreased GSH-Px ( $\mathrm{G} 3=\mathrm{G} 4=0.6 \pm 0.2)$ and SOD $(\mathrm{G} 3=223.0 \pm 84.7 ; \mathrm{G} 4=146.1 \pm 40.8)$, and decreased fetal CAT activity (G3 $=22.4 \pm 10.6$; G4 $=34.4 \pm 14.1)$ and GSH-t (G3 = G4 = $0.3 \pm 0.2)$, compared to the non-diabetic groups $(\mathrm{G} 1$, untreated control; G2, treated). For G1, maternal GSH-Px $=0.9 \pm 0.2$ and SOD $=274.1 \pm 80.3$; fetal CAT $=92.6 \pm 82.7$ and GSH- $\mathrm{t}=0.6 \pm 0.5$. For G2, G. biloba treatment caused no toxicity and did not modify maternal or fetal-placental data. EGb 761 at the nontoxic dose used $\left(200 \mathrm{mg} \mathrm{kg}^{-1}\right.$ day $^{-1}$ ), failed to modify the diabetes-associated increase in maternal glycemia, decrease in pregnancy rate, decrease in antioxidant enzymes, and impaired fetal development when the rats were treated throughout pregnancy (21 days).
\end{abstract}

Key words

- Ginkgo biloba

- Diabetes mellitus

- Pregnancy

- Reproductive outcome

- Oxidative stress

.......................
Diabetes mellitus is one of the most common endocrine disorders. During pregnancy, diabetes causes reproductive abnormalities that enhance spontaneous abortion, congenital anomalies, and neonatal morbidity and mortality $(1,2)$. Excessive oxidative stress has been implicated in the pathology and complications of diabetic pregnancy (3).

There is evidence that medicinal herb extracts that have different radical scavenging properties may provide powerful antioxidant defenses for the organism. Since time 
immemorial, patients with diabetes have been treated orally in folk medicine with a variety of plant extracts, such as Allium sativum, Momordica charantia, Trigonella foenumgraceum, and Ginkgo biloba (4). G. biloba leaf extract (EGb 761) is sold either as a single-herbal preparation, ground leaves, or in combination with botanicals such as Ginseng or Cola. EGb 761 has wide beneficial effects in severe disease states (5).

Since oxidative damage has been implicated in the etiology of diabetic complications (6), we thought that G. biloba extract (EGb 761) may improve the maternal and fetal-placental results in experimental diabetic pregnancy. The aim of the present study was to evaluate the effect of G. biloba treatment on maternal reproductive performance and on the maternal and fetal liver antioxidant systems in streptozotocin-induced diabetic rats.

Three-month-old female and male Wistar rats weighing about $200 \mathrm{~g}$ were obtained from the São Paulo State University (UNESP) breeding center. The protocols for animal use and the procedures needed for the experiments described here were approved by the Animal Ethics Committee of the Botucatu School of Medicine, UNESP, Brazil.

Diabetes was induced in these animals by intravenous injection of streptozotocin (Sigma, St. Louis, MO, USA) 7 days before the mating period as previously described (7). An intravenous dose of $40 \mathrm{mg} / \mathrm{kg}$ body weight was used to produce a permanent severe diabetic state (glycemia $>200 \mathrm{mg}$ / $\mathrm{dL})$. Blood glucose levels were measured on days $0,5,14$, and 21 of pregnancy at approximately 9:00 am using glucose oxidase reagent strips (One Touch Ultra, Johnson \& Johnson $^{\circledR}$, Milpitas, CA, USA). Only rats with glucose levels higher than $200 \mathrm{mg} / \mathrm{dL}$ were used in the diabetic groups.

The females in the diabetic and nondiabetic groups were then mated overnight with non-diabetic male rats, one week after streptozotocin injection. Daily vaginal smears were collected to detect the presence of sperm (day 0 of pregnancy). Four experimental groups were studied: G1 = non-diabetic untreated rats (control), G2 = nondiabetic rats treated with $200 \mathrm{mg} / \mathrm{kg}$ G. biloba extract $(\mathrm{EGb} 761), \mathrm{G} 3$ = diabetic untreated rats, and G4 = diabetic rats treated with 200 $\mathrm{mg} / \mathrm{kg}$ EGb 761. EGb 761 (in a liquid and pure state) was acquired from Altana Pharma Ltda. (Santo Amaro, SP, Brazil). The treatment was given orally once a day by gavage (intragastric route) in a dose of $200 \mathrm{mg} / \mathrm{kg}$ from day 0 to 20 of pregnancy of rats. The maximum volume administered was $2.0 \mathrm{~mL} / \mathrm{rat}$.

All animals were killed by decapitation on day 21 of pregnancy. The numbers of implantations, live and dead fetuses, and resorptions (embryonic deaths) were counted. Hepatic perfusion was carried out using $0.9 \%$ saline solution to remove the maternal liver for biochemical determinations. The preimplantation loss rate was calculated as number of corpora lutea - number of implantations x 100/number of corpora lutea, while the post-implantation loss rate was calculated as: number of implantations - number of live fetuses x 100 / number of implantations. The mean birth weight of the control pups (G1) was $5.2 \pm 0.6 \mathrm{~g}$. Newborns in the experimental groups whose birth weights did not diverge more than \pm 1.0 standard deviation (SD) from the G1 mean (i.e., those that were within the 4.6- to 5.8-g range) were classified as appropriate for gestational age. Those whose weights were at least 1.0 SD greater than the G1 mean birth weight were classified as large for gestational age. Those whose birth weights were at least 1.0 SD lower than the G1 mean birth weight were classified as small for gestational age (8).

Newborn rats from each group were killed by decapitation, and liver tissue was collected for biochemical determinations. Superoxide dismutase (SOD) antioxidant activity was determined by the method described by McCord and Fridovich (9). Total glutathione (GSH-t) is reported as $\mu \mathrm{mol} / \mathrm{g}$ 
liver and was determined by the method of Tietze (10), as modified by Akerboom and Sies (11). Glutathione peroxidase (GSH-Px) activity is reported as IU/mg protein and was evaluated by the method of Sies et al. (12). Catalase (CAT) activity is reported as IU/mg protein and was determined by the method of Beutler (13).

Data are reported as means $\pm \mathrm{SD}$. ANOVA followed by the Student-NewmanKeuls test was used to compare the mean values for the numbers of corpora lutea, implantations and live fetuses, fetal and placental weights, placental index, glycemia, and oxidative stress biomarkers, among the experimental groups. Fisher's exact test was used to calculate pre- and post-implantation loss rates and fetal classification (14). P < 0.05 was taken to be statistically significant.

The glycemic levels were significantly higher $(>300 \mathrm{mg} / \mathrm{dL})$ in diabetic rats (G3) compared to non-diabetic rats $(\mathrm{G} 1)$. EGb 761 treatment did not modify blood glucose levels of the non-diabetic (G2) and diabetic rats (G4) (data not shown). In the literature (15) and in folk medicine this plant is used as a hypoglycemic agent. Nevertheless, according to Sinzato et al. (16), the dose of $200 \mathrm{mg}$ $\mathrm{kg}^{-1}$ day $^{-1}$ of EGb 761 was insufficient to cause changes in the glycemic levels of these animals.

The numbers of corpora lutea, implantations, live fetuses and appropriate for gestational age and large for gestational age fetuses, the rate of term pregnancy, maternal weight gain, and fetal weight were lower in the untreated diabetic group (G3) than in the untreated non-diabetic group (G1). The numbers of resorptions and small for gestational age fetuses, and the post-implantation loss rate and placental weight and index were greater in G3 than in G1. EGb 761 treatment of non-diabetic rats (G2) did not modify maternal reproductive performance parameters or fetal development compared to G1. Diabetic rats treated with EGb 761 presented similar reproductive performance and fetal development data in relation to G3 (Table 1).

In women with uncontrolled diabetes, miscarriages are frequent (17). In the diabetic rats there was a similar outcome, with higher numbers of resorptions and increased rates of post-implantation loss leading to decreased numbers of live fetuses. EGb 761 treatment did not prevent the development of these complications in the diabetic rats and did not interfere with these parameters in non-diabetic rats. These results also demonstrate that this standardized G. biloba extract was safe for both maternal and fetal outcomes (in non-diabetic and diabetic rats) under the conditions employed here.

The placental weight and index were greater in the diabetic rats, regardless of treatment with EGb 761 (Table 1). However, this increase in placental weight was insufficient for fetal nourishment. As a result, there was a higher proportion of small for gestational age fetuses in the diabetic groups, thus confirming the existence of placental dysfunction in maternal-placental-fetal exchanges $(18,19)$.

The CAT activity sampled from the offspring of G2 rats was lower than in G1 (Table 2). This antioxidant enzyme was impaired by treatment with the extract in the present study. No evidence of this effect has been reported in the literature.

Maternal SOD and GSH-Px activity and fetal CAT activity and GSH-t concentration sampled from the untreated diabetic group (G3) were lower than in G1. Diabetic rats treated with EGb 761 presented alterations in maternal and fetal antioxidant biomarkers that were similar to those found in G3 (Table 2). Hyperglycemia increases reactive oxygen species and diminishes the antioxidant system and therefore favors increased oxidative stress $(2,19)$. In our study, the diabetic rats presented reductions in the first line of antioxidant defense (SOD and GSH$\mathrm{Px}$ ), thus confirming their exacerbated oxidative stress, as also shown in the literature (20). EGb 761 treatment did not improve the 
antioxidant defences of diabetic rats. Antioxidant therapy would perhaps be more effective in diabetic pregnancies with the use of pure antioxidants like $\alpha$-tocopherol or ascorbate (20), but not with EGb 761, which may upset the balance between pro-oxidants and scavengers in diabetic pregnancy. The fetuses of diabetic rats, whether treated with EGb 761 or not, presented reduced CAT and GSH-t antioxidant enzyme activity. Our re-

Table 1. Reproductive performance of diabetic and non-diabetic rats at term treated or not with Ginkgo biloba (EGb).

\begin{tabular}{|c|c|c|c|c|}
\hline \multirow[t]{2}{*}{ Groups } & \multicolumn{2}{|c|}{ Non-diabetic } & \multicolumn{2}{|c|}{ Diabetic } \\
\hline & G1 & G2 (EGb treated) & G3 & G4 (EGb treated) \\
\hline No. of mated females & 13 & 13 & 18 & 19 \\
\hline Pregnancy at term & $100 \%$ & $100 \%$ & $61 \%{ }^{*}$ & $74 \% *$ \\
\hline Mean maternal weight gain $(\mathrm{g})$ & $135.9 \pm 20.8$ & $128.9 \pm 14.7$ & $75.6 \pm 17.1^{*}$ & $82.1 \pm 30.3^{*}$ \\
\hline No. of corpora lutea & $13.8 \pm 1.5$ & $14.0 \pm 1.7$ & $12.7 \pm 1.6^{*}$ & $13.1 \pm 1.9^{*}$ \\
\hline No. of implantations & $13.1 \pm 1.8$ & $12.9 \pm 2.0$ & $11.0 \pm 1.8^{*}$ & $12.0 \pm 2.3^{*}$ \\
\hline Total No. of live fetuses & 156 & 156 & 103 & 138 \\
\hline No. of live fetuses & $12.0 \pm 2.3$ & $12.0 \pm 1.6$ & $9.4 \pm 3.0^{*}$ & $9.9 \pm 1.5^{*}$ \\
\hline No. of resorptions & $1.1 \pm 1.0$ & $0.7 \pm 0.8$ & $1.6 \pm 1.9^{*}$ & $2.1 \pm 2.9^{*}$ \\
\hline Pre-implantation loss & $4.8 \%$ & $7.3 \%$ & $13.3 \%$ & $8.5 \%$ \\
\hline Post-implantation loss & $8.9 \%$ & $6.5 \%$ & $16.2 \% *$ & $15.1 \% *$ \\
\hline Mean fetal weight (g) & $5.2 \pm 0.6$ & $5.2 \pm 0.4$ & $4.1 \pm 0.4^{\star}$ & $3.9 \pm 0.6^{*}$ \\
\hline Mean placental weight $(\mathrm{g})$ & $0.5 \pm 0.1$ & $0.5 \pm 0.1$ & $0.7 \pm 0.1^{\star}$ & $0.7 \pm 0.1^{*}$ \\
\hline Mean placental index & $0.10 \pm 0.02$ & $0.10 \pm 0.01$ & $0.18 \pm 0.04^{*}$ & $0.17 \pm 0.05^{*}$ \\
\hline SGA fetuses & $14.1 \%$ & $10.4 \%$ & $76.5 \% *$ & $80.4 \% *$ \\
\hline AGA fetuses & $75.0 \%$ & $87.0 \%$ & $21.6 \% *$ & $19.6 \% *$ \\
\hline LGA fetuses & $10.9 \%$ & $2.6 \%$ & $1.9 \%^{*}$ & $0.0 \%^{*}$ \\
\hline
\end{tabular}

Data are reported for total number of newborns per group and mean $\pm S D$ or as percent. There were no dead fetuses. SGA = small for gestational age; $A G A$ = adequate for gestational age; $L G A$ = large for gestational age.

${ }^{*} \mathrm{P}<0.05$ compared to the non-diabetic groups (G1 and G2; Student-Newman-Keuls test).

Table 2. Oxidative stress biomarkers of diabetic and non-diabetic female rats and their offspring at term treated or not with Ginkgo biloba (EGb).

\begin{tabular}{lccccc}
\hline \multirow{2}{*}{ Groups } & \multicolumn{2}{c}{ Non-diabetic } & & \multicolumn{2}{c}{ Diabetic } \\
\cline { 2 - 3 } \cline { 5 - 6 } & G1 & G2 (EGb treated) & & G3 & G4 (EGb treated) \\
\cline { 5 - 6 } Maternal liver enzymes & & & & \\
CAT (IU/mg protein) & $324.4 \pm 97.5$ & $320.5 \pm 102.1$ & & $283.5 \pm 98.5$ & $253.5 \pm 92.9$ \\
SOD (IU/mg protein) & $274.1 \pm 80.3$ & $256.1 \pm 80.8$ & & $223.0 \pm 84.7^{*}$ & $146.1 \pm 40.8^{*}$ \\
GSH-Px (IU/mg protein) & $0.9 \pm 0.2$ & $0.9 \pm 0.3$ & & $0.6 \pm 0.2^{*}$ & $0.6 \pm 0.2^{*}$ \\
GSH-t ( $\mu$ mol/g liver) & $6.8 \pm 1.0$ & $7.5 \pm 1.3$ & & $6.5 \pm 1.5$ & $5.6 \pm 1.4$ \\
Fetal liver enzymes & & & & \\
CAT (IU/mg protein) & $92.6 \pm 82.7$ & $41.4 \pm 22.9^{*}$ & & $22.4 \pm 10.6^{*}$ & $34.4 \pm 14.1^{*}$ \\
SOD (IU/mg protein) & $82.5 \pm 12.5$ & $104.0 \pm 32.9$ & & $118.7 \pm 22.5$ & $98.6 \pm 29.7$ \\
GSH-Px (IU/mg protein) & $0.07 \pm 0.04$ & $0.07 \pm 0.03$ & & $0.09 \pm 0.04$ & $0.09 \pm 0.04$ \\
GSH-t ( $\mu$ mol/g liver) & $0.6 \pm 0.5$ & $0.4 \pm 0.3$ & & $0.3 \pm 0.2^{*}$ & $0.3 \pm 0.2^{*}$
\end{tabular}

Data are reported as mean \pm SD for 9 animals/group. CAT = catalase; SOD = superoxide dismutase; GSH-Px = glutathione peroxidase; $\mathrm{GSH}-\mathrm{t}=$ total glutathione.

${ }^{*} \mathrm{P}<0.05$ compared to the non-diabetic group (G1; Student-Newman-Keuls test). 
sults disagree with a literature report (5) that daily ingestion of EGb 761 (120 mg/day for 3 months) significantly decreased platelet malondialdehyde-thiobarbiturate levels in subjects with confirmed type 2 diabetes mellitus, thus suggesting that this plant has an antioxidant effect. As our treatment period was shorter than the one of Kudolo et al. (5), we suggest that short-treatment period might be one of the factors to explain the lack of positive antioxidant results.

In conclusion, EGb 761 was not toxic at the dose level used in this study (200 mg $\mathrm{kg}^{-1}$ day $^{-1}$ ), but it failed to modify the diabetes-associated increase in maternal glycemia, decrease in pregnancy rate, decrease in antioxidant enzymes, and impaired fetal development, when these rats were treated throughout pregnancy (21 days).

\section{Acknowledgments}

The authors thank Mr. Benedito Claudio da Silva and Ms. Sandra Sinzato for technical assistance.

\section{References}

1. Yang J, Cummings EA, O'Connell C, Jangaard K. Fetal and neonatal outcomes of diabetic pregnancies. Obstet Gynecol 2006; 108: 644-650.

2. Eriksson UJ, Cederberg J, Wentzel P. Congenital malformations in offspring of diabetic mothers - animal and human studies. Rev Endocr Metab Disord 2003; 4: 79-93.

3. Zhao Z, Reece EA. Experimental mechanisms of diabetic embryopathy and strategies for developing therapeutic interventions. $J$ Soc Gynecol Investig 2005; 12: 549-557.

4. Volpato GT, Damasceno DC, Calderon IMP, Rudge MVC. Revisão de plantas brasileiras com comprovado efeito hipoglicemiante no controle do diabetes mellitus. Rev Bras PI Med 2002; 4: 35-45.

5. Kudolo GB, Delaney D, Blodgett J. Short-term oral ingestion of Ginkgo biloba extract (EGb 761) reduces malondialdehyde levels in washed platelets of type 2 diabetic subjects. Diabetes Res Clin Pract 2005; 68: 29-38.

6. Sanders RA, Rauscher FM, Watkins JB III. Effects of quercetin on antioxidant defense in streptozotocin-induced diabetic rats. $J$ Biochem Mol Toxicol 2001; 15: 143-149.

7. Damasceno DC, Volpato GT, Calderon IM, Aguilar R, Rudge MV. Effect of Bauhinia forficata extract in diabetic pregnant rats: maternal repercussions. Phytomedicine 2004; 11: 196-201.

8. Volpato GT, Damasceno DC, Miranda MRF, Sabbag-Filho D, Calderon IMP, Rudge MVC. Mixture of vitamin C, hesperidin and piperidol exposure in pregnancy: maternal-fetal repercussions. Rev Bras Cienc Farm 2006; 42: 77-82.

9. McCord JM, Fridovich I. Superoxide dismutase. An enzymic function for erythrocuprein (hemocuprein). J Biol Chem 1969; 244: 60496055.

10. Tietze F. Enzymic method for quantitative determination of nanogram amounts of total and oxidized glutathione: applications to mammalian blood and other tissues. Anal Biochem 1969; 27: 502-
522.

11. Akerboom TP, Sies H. Assay of glutathione, glutathione disulfide, and glutathione mixed disulfides in biological samples. Methods Enzymol 1981; 77: 373-382.

12. Sies $\mathrm{H}$, Koch $\mathrm{OR}$, Martino $\mathrm{E}$, Boveris $\mathrm{A}$. Increased biliary glutathione disulfide release in chronically ethanol treated rats. FEBES Lett 1979; 103: 287-290.

13. Beutler E. Red cell metabolism: A manual of biochemical methods. New York: Grune \& Stratton; 1984.

14. Zar JH. Biostatistical analysis. New Jersey: Prentice-Hall; 1999.

15. Tanaka S, Han LK, Zheng YN, Okuda H. Effects of the flavonoid fraction from Ginkgo biloba extract on the postprandial blood glucose elevation in rats. Yakugaku Zasshi 2004; 124: 605-611.

16. Sinzato S, Calderon IMP, Damasceno DC, Volpato GT, et al. Tratamento de ratas diabéticas prenhes com extrato de Morus nigrum: Repercussões sobre a hiperglicemia e o sistema antioxidante maternos e as malformações fetais. Arq Bras Endocrinol Metab 2004; 48 (Suppl 1): S188.

17. Calderon IMP, Rudge MVC, Ramos MD, Peraçoli JC. Estudo longitudinal, bioquímico e histoquímico de placentas de ratas diabéticas - relação com a macrossomia e o retardo de crescimento intrauterino. Rev Bras Ginecol Obstet 1999; 21: 91-98.

18. Volpato GT, Damasceno DC, Sinzato S, Cervelin V, Nicolielo H, Sarti M, et al. Avaliação do efeito do extrato aquoso das folhas de Morus nigra (Amora) no binômio diabete e gravidez. Diabetes Clínica 2005; 5: 340-345.

19. Damasceno DC, Volpato GT, de Mattos Paranhos Calderon I, Cunha Rudge MV. Oxidative stress and diabetes in pregnant rats. Anim Reprod Sci 2002; 72: 235-244.

20. Cederberg J, Eriksson UJ. Antioxidative treatment of pregnant diabetic rats diminishes embryonic dysmorphogenesis. Birth Defects Res A Clin Mol Teratol 2005; 73: 498-505. 